study number 1, "Studded and studless tires in fatal wintertime road accidents" was based on accident data analysis. The study 2 , "The socio-economical consequences of Ice grip approval" was based on literature analysis. The study 3, "The winter tyre type effects on the grip and wear of packed snow and ice" was a field test study.

Results

- In Finland, 12\% of the traffic exposure of passenger cars and vans in winter is driven by studless winter tires. If everyone in Finland would use studded tires, we would have one deadly accident per year less.

- There is no ice grip demands for the winter tires used in Finland. If such demand will be deployed today, there will be 0.5 million $€$ yearly societal savings per year. If the use of studless tires increase as planned, the effects of ice grip approval will be multifold.

- Studded tires have an external safety effect, they make ice more rough. According to tests in test field, 50\% of studded tires ensured good friction conditions for all kind of winter tires.

Conclusions Use of studded tires offer still remarkable traffic safety benefits in winter time. Because there seem to be need to decrease the proportion of studded tires in large cities (studded tires may promote air quality problems), it's still important to understand, how we can minimise the negative traffic safety effects of this decrease. By deploying ice grip demands, we can be assured, that the approved studless tires meet the winter traffic demands. It's also important to remember, that if the proportion of studded tires will fall below 50\%, there is high risk for increasing slipperiness.

\section{ACCEPTANCE AND IMPACTS OF A REAL TIME REINDEER WARNING SERVICE}

Elina Aittoniemi, Pirkko Rämä. VTT Technical Research Centre of Finland

\subsection{6/injuryprev-2016-042156.396}

Background About 4000 reindeer die each year in traffic, causing significant costs. This study investigated the acceptability of a real-time reindeer warning service and its potential impacts on driver behaviour, foresight and traffic safety.

Methods Professional heavy goods vehicle drivers participating in the field test on two main roads in Northern Finland received real time warnings based on sightings of reindeer on or near the road. The information was provided by the same group of drivers and a group of reindeer herders.

The warning system was a simple smart phone application and was designed to be easy to use. When a driver saw reindeer near the road, he touched a circle on the screen of a smart phone installed in their vehicle, sending the warning to all nearby drivers using the application. The warnings were in effect within an area of radius $500 \mathrm{~m}$ from the initial warning for the following 2-4 hours.

Results The impacts of the service were evaluated by driver questionnaires and interviews. The drivers were interviewed twice, after about 6 and 12 months use of the service. 23 drivers participated in the interviews. In addition, also driving companies, reindeer herders and other stakeholders and experts were interviewed. The majority of drivers assessed the service useful. They especially liked the possibility to foresee unexpected situations. Drivers valued service simplicity. It was estimated that, if installed in every vehicle, the service could lead to a decrease in reindeer accidents by 9.7-17.8\%, corresponding to a reduction of 395-725 accidents annually. Regarding all injury accidents in the area, the service was estimated to cause a reduction of $0.76-$ $1.52 \%$ corresponding to $2-4$ injury accidents annually.

Conclusions The service worked well and was well received by its users. The results of the trial were promising.

\section{7 SNOWMOBILE-RELATED INJURIES IN U.S. EMERGENCY DEPARTMENTS 2001-2013}

Christopher Peterson, Charles Jennissen. Department of Emergency Medicine, University of lowa Carver College of Medicine, USA

\subsection{6/injuryprev-2016-042156.397}

Background Snowmobiling is a popular form of winter recreation, but adverse events can lead to significant injury. Our objective was to determine the demographics and risk factors for snowmobile-related injuries seen in Emergency Departments (EDs).

Methods ED visits related to snowmobile operation were identified in the National Electronic Injury Surveillance System (NEISS) database, which collects information from a national probability sample of U.S. hospitals. Descriptive and statistical analyses were performed.

Results From 2002-2013, 1,944 snowmobile-related injuries were identified in the NEISS database. This corresponds to a national estimate of 135,032 snowmobile-related ED visits during the study period. There was a trend of decreasing injuries over time with a national estimate of 12,862 in 2002 and 9,270 in 2013 (average decrease of 499 per year, 95\% CI: 89.9-907.7). Most commonly injured were 19-29 year olds, accounting for $30 \%$ of the total; $19 \%$ were paediatric patients. About threefourths were male. The most common mechanisms of injury involved falling off $(22 \%)$, striking a stationary object $(16 \%)$, and rolling the vehicle $(13 \%)$. Mechanisms that had the greatest admission rates included events involving a drop-off (50\%), ejections (25\%) and motorised vehicle collisions (22\%). Helmets were reported as being used in $11.4 \%$. Patients wearing a helmet had a $63 \%$ reduced odds of requiring inpatient admission compared to those without $(\mathrm{p}=0.03)$. Speed was reported in only $7 \%$ of cases. A higher proportion of those operating at speeds estimated $\geq 35 \mathrm{mph}$ were admitted $(24 \%)$ as compared to those with lower speeds (15\%).

Conclusions Snowmobilers without helmets were more likely to require hospital admission. Snowmobilers should be especially wary of terrain changes, other vehicles in the area, and being ejected, as these mechanisms had injuries requiring higher rates of inpatient treatment. 